\title{
O EFEITO ESTÉTICO: FINALIDADE SEM FIM
}

\author{
Flávio Desgranges ${ }^{1}$
}

Resumo

O autor analisa o efeito estético proposto ao espectador a partir das alterações recentes na cena teatral. Calcado nas produções teóricas de Jacques Rancière, Wolfgang

Iser e Hans-Robert Jauss, compreende que o efeito das experiências teatrais na contemporaneidade está marcado pela ausência de um fim definido a priori. Dizer que essa produção artística não tem um fim, contudo, não quer dizer que seja desprovida de finalidade.

Palavras-chave: teatro, espectador, recepção, efeito estético, contemporaneidade.

Abstract

The author analyses the aesthetic effect proposed to the spectator by the recent changes in the theatrical scene.

Drawing on the theoretical productions of Jacques

Rancière, Wolfgang Iser and Hans Robert Jauss, his understanding is that the effect of the theatre experiences nowadays is marked by the absence of an order defined a priori. To say that artistic production is not an end, however, does not mean that it is devoid of purpose.

Keywords: theatre, spectator, reception, aesthetic effect, contemporary. 
É isto que significa o termo emancipação: o rompimento da fronteira entre aqueles que agem e aqueles que observam, entre indivíduos e membros de um corpo coletivo.

Jacques Rancière

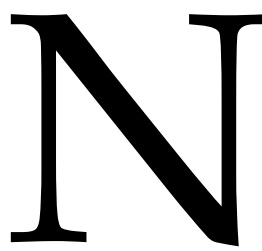

livro Le spectateur émancipé ${ }^{2}$ - com tradução para o português ${ }^{3}$ em que se propõe a analisar a emancipação do espectador em face das manifestações artísticas contemporâneas, Jacques Rancière traça uma comparação da atitude proposta ao leitor no campo da arte com a participação conferida aos alunos em um processo pedagógico. Para isso, Rancière se vale das reflexões concebidas em outro livro seu, intitulado $O$ Mestre Ignorante ${ }^{4}$, em que aborda as excêntricas opções pedagógicas de Joseph Jacotot, professor francês do início do século XIX.O que marca a linha educacional adotada por esse mestre é justamente o fato de colocarse em situações em que sua própria ignorância configura-se como marca fundamental do processo instaurado. Seu primeiro desafio começa em 1818, quando convidadoa assumir o cargo de professor nos Países Baixos: seus alunos não falavam francês e ele ignorava totalmente o holandês, não havia pois uma língua comum em que pudessem estabelecer uma situação educacional. Naquela época havia sido publicada uma versão bilíngue de As Aventuras de Telêmaco, de Fénelon, um dos romances franceses mais lidos durante o século XVIII, e Jacotot viu ali uma saída, propôs que os alunos lessem o livro e, por conta própria, escrevessem em francês o que pensavam de tudo o que haviam lido. Esperava por barbaridades, pois:

1 Professor livre-docente do Departamento de Artes Cênicas da USP. Autor dos seguintes livros: Pedagogia do Espectador, Hucitec, 2003; Pedagogia do Teatro: provocação e dialogismo, Hucitec, 2006.

2 RANCIÈRE, Jacques. Le spectateur émancipé. Paris: La fabrique, 2008.

3 RANCIĖRE, Jacques. O Espectador emancipado. Lisboa: Orfeu Negro, 2010.

4RANCIĖRE, Jacques. OMestre lgnorante - cinco lições sobre a emancipação intelectual. Belo Horizonte, Autêntica, 2005.
Como, de fato, poderiam todos esses jovens, privados de explicações, compreender e resolver dificuldades de uma língua nova para eles? De toda forma, era preciso verificar até onde esse novo caminho, aberto por acaso, os havia conduzido e quais os resultados desse empirismo desesperado. Mas, qual não foi sua surpresa quando descobriu que seus alunos, abandonados a si mesmos, se haviam saído tão bem dessa situação quanto o fariam muitos franceses! (apud RANCIÈRE, 2005, p. 18-19).

Até então Jacotot acreditava que a principal tarefa dos mestres era a de transmitir seu saber aos alunos, não se tratava, bem sabia, de "entupir os alunos de conhecimentos, fazendo-os repetir como papagaios, mas, também, que é preciso evitar esses caminhos do acaso, onde se perdem os espíritos ainda incapazes de distinguir o essencial do acessório" (RANCIËRE, 2005, p. 19). A atitude adotada pelo professor deveria interligar com clareza causa e consequência, tecer relações evidentes entre os métodos educacionais propostos e o fim almejado, estabelecido a priori; assim o aluno poderia progredir, ao apropriar-se racionalmente do conhecimento, que o levaria à formação do julgamento e do gosto.

A experiência nos Países Baixos colocava em questão uma evidência de todo o sistema de ensino: a necessidade de explicações; sozinhos os alunos haviam buscado e combinado as palavras francesas correspondentes às que conheciam, sem explicações sobre ortografia e conjugações. Explicar alguma coisa a alguém parece, antes de mais nada, analisa Rancière, demonstrar-lhe que não poderia compreender por si só; o que cria uma dependência permanente do mestre, de quem o aluno sempre precisará, e a quem sempre recorrerá para obter as necessárias explicações sobre os novos assuntos. Somente compreenderá aquilo o que lhe for explicado, pois não experimentou entender por si mesmo, do seu modo, concebendo estratégias e táticas próprias de aprendizado. 
O texto lhes foi proposto não na condição de alunos, ou mesmo na condição de sábios, mas na condição de homens, e a resposta ao texto poderia ser dada como se responde a alguém que lhe dirige uma palavra, sob o signo da igualdade. Se a condição de igualdade parecia fundamental, também o era a disponibilidade para o processo e a vontade de constituir aprendizagem. "Podia-se aprender sozinho, e sem mestre explicador, quando se queira, pela tensão do seu próprio desejo ou pela contingência da situação" (RANCIÈRE, 2005, p. 30). A função do mestre, por sua vez, não se tornava desprezível, permanecia necessária; sem as propostas do mestre, pensadas em face de uma determinada situação, não haveria aprendizagem.

Jacotot, ao perceber que não era o saber do mestre que ensinava oaluno, mas o modo de abordagem do conhecimento, dedicouse, então, a ensinar o que ignorava, e passou a investir em novas tentativas, repetindo propositalmente o que havia descoberto por acaso. "Ele se pôs, assim, a ensinar duas matérias em que sua incompetência era patente, a pintura e o piano" (RANCIÈRE, 2005, p. 33); experiências estas que pareceram suficientes para esclarecê-lo de que pode-se de fato ensinar o que se ignora, desde que se estimule o aluno a utilizar sua própria inteligência no processo.

A partir da análise acerca das experiências de Jacotot, Rancière se debruça sobre aspectos da teatralidade, traçando uma analogia entre os procedimentos pedagógicos do mestre ignorante e as propostas teatrais recentes. Para o teórico francês, as duas principais correntes vanguardistas da cena teatral, advindas, tanto das resoluções do teatro épico de Brecht, quanto das proposições do teatro da crueldade de Artaud, trazem consigo um caráter explicativo, ou, melhor dizendo, estruturam-se como propostas artísticas que definem um fim prévio a ser atingido, que querem alcançar um intento determinado a priori; o que retiraria do espectador a possibilidade de atuar por conta própria, de definir os rumos e fins de sua participação no evento, de inventar um processo de leitura.

\begin{abstract}
Estas são as atitudes fundamentais que resumem o teatro épico de Brecht e o teatro da crueldade de Artaud: para um o espectador deve tomar distância, para o outro ele deve perder toda distância; para um ele deve afinar o seu olhar, para o outro ele deve abdicar da própria posição de observador. Os empreendimentos modernos de reforma do teatro têm constantemente oscilado entre esses dois pólos, da investigação distante e da participação vital, sob o risco de entremear seus princípios com seus efeitos (RANCIÈRE, 2008, p. 10-11).
\end{abstract}

Para Brecht, a reforma do teatro passa pela restauração de sua função de assembleia, em que as pessoas do povo possam tomar consciência de sua situação e discutir seus interesses. "Segundo o paradigma brechtiano, a mediação teatral os torna conscientes da situação social, colocando-os em condição e desejosos de agir para transformá-la". (RANCIÈRE, 2008, p. 14). Para Artaud, o teatro se constitui como ritual de purificação, que atue sobre o espectador como uma "terapêutica da alma" (ARTAUD, 1985, p. 109), de modo que os elementos da cena possam atingi-lo a ponto de deixar uma marca indelével e processar uma profunda transformação; os participantes são retirados da posição de espectadores, "em lugar de estarem diante de um espetáculo, são envolvidos pela performance, lançados em um círculo de ação que lhes fornece uma energia coletiva" (ARTAUD, 1985, p. 109). Tanto em uma vertente teatral, quanto na outra, a atitude dos espectadores depende fundamentalmente dos artistas, que definem o modo de atuação necessário para a boa realização do evento.

A partir dessa compreensão dos princípios do teatro da vanguarda e dos efeitos que pretende conseguir, Rancière coloca em questão a emancipaçãointelectual proposta por algumas práticas teatrais contemporâneas, em que as atitudes a 
serem desempenhadas pelo espectador ainda se mostram definidas a priori. Mesmo que recusem a noção de que o teatro deve apresentar uma mensagem, ou apontar uma saída clara para os embates políticos e sociais, estas proposições artísticas esperam atingir consequências determinadas: seja montadas com dispositivos que vão sendo armados e deflagrados à medida que o espectador processa a leitura da obra, de modo a conduzi-lo para uma conclusão estabelecida previamente; ou calcadas no intuito de reaver a noção perdida de comunidade, determinada a partir do pressuposto de que o teatro deve opor-se ao individualismo da indústria cultural, e estabelecem o fim do evento na constituição de um coletivo de espectadores; ou mesmo tomando a intervenção do espectador como um fim em si, o que sustentaria o princípio da proposta estética e justificaria a participação como efeito a ser alcançado, tirando-o da inércia em que se encontra. Outro modo de proposição apontado pelo autor francês pode ser identificado nas tentativas de hibridização dos meios artísticos, mesclando o real com o virtual, o orgânico com o mecânico e o informático, valendo-se do esfacelamento das fronteiras e da confusão de papéis para ampliar os efeitos da performance, sem sequer questionar os seus princípios. De todo modo, "mesmo que o dramaturgo ou o encenador não saibam o que querem que o espectador faça, sabem ao menos uma coisa: que o espectador deve fazer uma coisa, atravessar o abismo que separa a atividade da passividade" (RANCIÈRE, 2008, p. 18).

Trata-se, portanto, de problematizar a tradição dramática naquilo que carrega de coordenação dos efeitos a serem obtidos, mas também de colocar em questão práticas artísticas substitutivas que mantenham a mesma lógica e que sustentem a posição do artista como a de detentor das regras e fins do jogo.

Estabelece-se, assim, uma lógica em que a atuação proposta ao espectador se aproxima de relações pedagógicas em que o papel do mestre é o de suprimir a distância entre o seu saber e a ignorância do ignorante; essas lições, contudo, não fazem outra coisa que restabelecer a distância cada vez que buscam desfazê-la, pois, nesse caso, "o mestre não é somente aquele que detém o saber ignorado pelo ignorante, mas tambémaqueleque sabe como constituirum objeto de conhecimento, em que momento e sob qual protocolo" (RANCIÈRE, 2008, p. 14). O saber, assim, se afirma não como um conjunto de conhecimentos, mas como uma posição, a ser mantida indefinidamente, e o que se ensina ao outro é a sua própria incapacidade de constituir objetos de saber, de produzir conhecimento.

O trabalho do mestre ignorante, por sua vez, é o de destruir a distância; o mestre ignorante não é o que nada sabe, mas o que ignora a ignorância do outro, sabendo que ele pode aprender como aprendeu todo o resto, que ele pode aprender não por se colocar na posição de sábio, mas por “colocar a sua experiência em palavras e essas palavras à prova, traduzindo as suas aventuras intelectuais para a leitura de outros, e contra-traduzindo as traduções que lhe são apresentadas de suas próprias aventuras" (RANCIÈRE, 2008, p. 17). O aluno aprende, nesse caso, como efeito da proposta que o estimula a experimentar, a buscar, a elaborar por conta própria.

A partir dessa analogia, a função do artista não é a de quem tem algo a ensinar ou de quem quer produzir algum efeito fundamental previamente constituído, e talvez se aproxime da de um propositor de jogos: jogos imprevisíveis de associações e dissociações; jogos de palavras, de imagens, de percepção, de afeto, jogos de linguagem, a serem elaborados e produzidos pelo próprio espectador (ou como quisermos chamar esse participante do evento); jogos em que as suas soluções sejam bem-vindas, bem como suas estratégias etáticasnomododeler as palavras e demais elementos e proposições de cena; jogos que movam sonhos, necessidades, vontades, compreendendo o espectador não como indivíduo apassivado, mas como ser desejante, que não está mais em busca de modelos, ou de interpretações prévias, ou 
de pedagogia moral, ou de quaisquer efeitos coordenados antecipadamente. Trata-se de inventar a cada momento procedimentos que façam valer um potencial já existente, e colocá-lo em jogo, deixando que cada qual trace seu próprio caminho pelos elementos de cena, quer se coloquem diante dele ou que o envolvam, sendo ou não convidado a um percurso interativo, de modo que possa perceber e traduzir do seu jeito o que lhe acontece, e produzir uma aventura sensível e intelectual marcada pela singularidade que o constitui.

(...) recolocar [a cena] em pé de igualdade, a partir da narração de uma história, da leitura de um livro, do olhar posto sobre uma imagem. Ela [esta maneira de tratar a cena] se propõe, em suma, a concebêla como uma nova cena da igualdade, em que performances heterogêneas se traduzem umas nas outras. Pois em todas essas performances se trata de relacionar aquilo o que sabemos com o que ignoramos, de colocarem-se ao mesmo tempo performers desempenhando suas competências e espectadores, diante de outros espectadores, observando o que essas competências podem produzir em um novo contexto. Os artistas, como pesquisadores, constroem uma cena em que a manifestação e o efeito de suas competências estão expostos, tornados incertos nos termos do novo idioma, que traduz uma nova aventura intelectual. $\mathrm{O}$ efeito do idioma não pode ser antecipado, e solicita espectadores que atuem como intérpretes ativos, que elaborem sua própria tradução para se apropriar da "história" e conceber a sua própria história. Uma comunidade emancipada é uma comunidade de contadores e de tradutores (RANCIÈRE, 2008, p. 28).

O âmbito político do acontecimento teatral, assim compreendido, se coloca no caráter dissensual de sua proposta em face dos regimes sensoriais vigentes, um dissenso que não se propõe como conflito de ideias e sentimentos, mas como divergência no modo de engendrar produções estéticas, no próprio modo de sentir, de pensar e de atuar em arte; e que toca a vida cotidiana através da "invenção de uma instância de enunciação coletiva que redesenha o espaço das coisas comuns" (RANCIÈRE, 2008, p. 66). Se a experiência estética toca o político, o faz por distinguir-se do padrão crítico apoiado predominantemente na representação mimética, que propõe uma rede de conexões que traça uma clara destinação e antecipa seus efeitos. Não se trata, pois, de adotar um novo habitus, ou incorporar um novo conhecimento, ou conquistar um comportamento virtuoso, mas, ao contrário, de dissociar-se de um certo modo de organização comum do sensível, e de propiciar outros modos de circulação da palavra, de exposição do visível, da produção de afetos; que pode contribuir para desenhar uma paisagem nova do dizível e do factível, em contraposição à configuração usual do possível. O que até pode ser pensado no âmbito da ação política, já que as formas de enunciação divergentes podem alcançar as táticas dos coletivos políticos, porém esse efeito estético "não define uma estratégia política da arte como tal, nem uma contribuição calculável da arte à ação política" (RANCIÈRE, 2008, p. 71).

Talvezsejaimportantenãoconcebermos o espectador dessa cena divergente como um terceiro, dito e compreendido como $o$ espectador, um outro, aquele que não sabe, alguém de quem estamos cuidando, protegendo os interesses e necessidades; porém, quem sabe, pensarmos a partir da nossa participação em acontecimentos artísticos, a partir de desejos e vontades próprios, como algo que de fato nos diga respeito, tratando "a emancipação de cada um de nós como espectador. Ser espectador não é uma condição passiva que se deve transformar em atividade, é a nossa situação normal" (RANCIÈRE, 2008, p. 23); a de quem age, conhece, questiona, investiga e relaciona a todo instante o que estamos vendo com aquilo o que vimos, dissemos, fizemos e sonhamos.

Ao nos voltarmos para o âmbito do efeito proposto pelas intervenções artísticas, a partir dos princípios estéticos traçados, algumas questões se apresentam: como 
compreender e operar a provocação de um efeito que se recusa ao efeito, ou de um efeito que se nega a ser coordenado a ponto de determinar as reações do espectador? Torna-se viável pensar um efeito que despreza a relação de causa e consequência? E mais: um efeito assim concebido não beira o vale-tudo? Como distinguir uma coisa da outra, uma proposta vigorosa de qualquer coisa que se faça de qualquer modo? E, por outro lado, toda e qualquer leitura é válida? Há critérios de distinção? Quais são eles? Como constituí-los? Essa distinção se faz ainda importante?

Se interpusermos aqui a acepção de que "quando uma época não consegue distinguir entre uma coisa e seu contrário, essa é uma época de barbárie" (COELHO, 1988 , p. 27), parece termos aí um ponto chave da experiência teatral de nosso tempo, que se estabelece como fio tênue e tenso entre o repúdio às regras e fins estabelecidos por outrem à nossa revelia, e o potencial de sentidos que pode ou não ser deflagrado a partir de determinados procedimentos artísticos.

Pode-se supor, também nesse âmbito, revendo as propostas do início do século XX, que as invenções recentes problematizam os procedimentos da vanguarda, valendose de intentos engendrados no período - o ato proposto ao espectador ainda toca o nervo dos pressupostos artísticos -, mas colocando-os em diálogo com as condições históricas atuais. Um dos aspectos sociais marcantes de nosso tempo está, como se sabe, na ausência de consenso coletivo, o que coloca em questão que uma proposta artística que queira operar um efeito previamente definido possa obter tal aceitação e adesão incondicional. O que podesercompreendido pela desautorização a qualquer palavra que se suponha detentora da verdade, ou de qualquer síntese, ou qualquer interpretação que se queira dotada de maior valor ou justeza que qualquer outra.

A impossibilidade de uma síntese que pretenda abarcar a vida em sua totalidade reverbera também no âmbito da leitura artística, o que nos leva a compreender que nenhuma interpretação de obra de arte pode se julgar detentora de um juízo de valor definitivo, pois a experiência com a arte pode abrir um amplo potencial de sentidos, suscitando análises múltiplas e singulares. No âmbito da recepção estética, Wolfgang Iser localiza historicamente a inviabilidade de uma interpretação que aspire abarcar todos os aspectos e significados de uma obra, de qualquer palavra que se diga autorizada a emitir um juízo taxativo sobre algo, como decorrente das condições políticas e sociais surgidas na década de 1960, especialmente a partir do movimento estudantil que eclode no período:

\begin{abstract}
Na revolta estudantil, esses pressupostos se tornaram relevantes para $\mathrm{o}$ desmascaramento crítico-ideológico. Por isso, a própria literatura começou a ser problematizada, e não apenas porque uma interpretação que reclamava validade normativa tenha produzido a ilusão de que ela era o próprio objeto. Nesse sentido, a situação política produziu o impulso necessário para se encontrar um acesso adequado à literatura contemporânea. Daí resultou uma mudança de orientação nas análises da literatura, que não mais se concentravam tanto na significação ou na mensagem, mas sim nos efeitos do texto e em sua recepção (ISER, 1996, p.10).
\end{abstract}

Pensar uma obra de arte ou um movimento artístico a partir do âmbito do efeito se faz como tentativa de mapear os procedimentos adotados e analisar como os artistas organizam os jogos propostos ao espectador, bem como os princípios que regem tais propostasartísticaseaefetividade dessas invenções em face das condições estéticas e históricas. Pretendemos aqui arriscar breves esboços desse mapeamento, tendo em vista a análise das propostas da teatralidade recente, a partir de sua recusa ao padrão dramático, que retiram a leitura do lugar que ocupava como significação, ou como entendimento do que o artista quer dizer, e instauram outro modo de análise e de função social para o teatro. 
A negação ao padrão vigente torna problemático o modo de organização da sensibilidade, tal como vigora nas produções espetaculares de nosso tempo, em suas mais diferentes formas e intentos, percorrendo as tantas realizações ficcionais, desde criações artísticas até noticiários jornalísticos, com presença marcante no material publicitário e na propaganda política - e isso para ficar restrito à produção mais contundente. $\mathrm{O}$ que, em uma perspectiva de análise da teatralidade, "tanto em seu contraste com o pano de fundo oferecido por outras formas artísticas, quanto contra o pano de fundo da experiência cotidiana de vida" (JAUS, 1994, p. 53), se configura como modo de estar e de idear o mundo, que (se) retroalimenta (n)a vida cotidiana, em seus pequenos gestos e intenções.

Não se trata de ver o teatro como um cãozinho furioso que persegue latindo a carruagem que passa, um teatro que se perde de si e se pensa como mera contraargumentação à espetacularização da sociedade, como contra-efeito à tecnologia e à capilaridade dos media. Porém, como algo que mantém a reflexão sobre si mesmo, pensando a sua função em face do tempo presente, em contraste com a teatralidade vigente em seus princípios e procedimentos, reelaborando permanentemente o aspecto crítico e inventivo de suas propostas; sem perder de vista, contudo, a necessária tensão com as condições estéticas e históricas. Condições estas, aliás, cuja escolha não é decidida nem pela estatística nem pela vontade subjetiva do teórico, "mas pela história do efeito: por "aquilo que resultou do acontecimento" (JAUS, 1994, p. 49); como um jogo de perguntas e respostas que vai marcando os pontos de intersecção e de cesura entre uma estética e suas antecessoras, e apontando possíveis relações destes pontos com o contexto social.

Não se trata também de uma inviabilização do drama em todos os seus aspectos, nem de dispensar seu amplo potencial envolvente e de vigoroso convencimento, nem a beleza e a produtividade histórica de sua realização mimética, mas fundamentalmente de uma ampliação de campo, de investigar outras maneiras de enunciação, de elaborar modos distintos de conceber o ato artístico e (por que não?) de gerir a vida social. Mesmo porque os elementos constituintes do drama continuam permeando as realizações teatrais; ou seja, as inovações recentes continuam se valendo de elementos da estética dramática: arremedos de personagens, franjas de identificação, fragmentos de fábulas, etc. O que se observa aqui, ressaltemos, é a desfuncionalização desta forma estética, oque acarreta mudanças novetor de leitura da cena, não mais necessariamente voltado para o acompanhamento da ação dramática ou centrado no ato de empatia.

\section{Referências bibliográficas}

ARTAUD, Antonin. O teatro e seu duplo. Rio de Janeiro: Max Limonad, 1985.

COELHO, José Teixeira. O queéação cultural. São Paulo: Brasiliense, 1988.

ISER, Wolfgang. Uma teoria do efeito estético. Vol. 1. São Paulo: Ed.34, 1996.

JAUSS, Hans Robert. A história da literatura como provocação à teoria literária. São Paulo: Ática, 1994.

RANCIÈRE, Jacques. Le spectateur émancipé. Paris: La fabrique, 2008.

O espectador emancipado. Lisboa:

Orfeu Negro, 2010.

.O mestre ignorante-cinco lições sobre

a emancipação intelectual. Belo Horizonte:

Autêntica, 2005. 